ISSN 1330-9862

original scientific paper

doi: $10.17113 / \mathrm{ftb} \cdot 54.02 .16 .4292$

\title{
Evaluation of Prebiotic Effects of High-Purity Galactooligosaccharides in vitro and in vivo
}

\author{
Ki Bae Hong ${ }^{1}$, Jae Hwan Kim², Hyuk Kon Kwon², Sung Hee Han ${ }^{1}$, Yooheon Park ${ }^{3 *}$ \\ and Hyung Joo Suh ${ }^{1 *}$ \\ ${ }^{1}$ Department of Public Health Sciences, Graduate School, Korea University, Seoul 07249, \\ Republic of Korea \\ ${ }^{2}$ Neo Cremar Co. Ltd., Seoul 05836, Republic of Korea \\ ${ }^{3}$ Dongguk University, Research Institute of Biotechnology, Goyang 10326, Republic of Korea
}

Received: June 1, 2015

Accepted: February 3, 2016

\begin{abstract}
Summary
Galactooligosaccharides (GOS) are an important class of dietary prebiotics that exert beneficial effects on intestinal microbiota and gut barrier function. In this study, high-purity GOS (HP-GOS) were investigated in vitro and in vivo and confirmed as prebiotic ingredients in rat diet. HP-GOS were successfully produced using a two-step process, enzymatic hydrolysis and fermentation by yeast. They were found to serve as a good substrate and carbon source for supporting the growth of probiotic bacteria more effectively than other commercial GOS. Following administration of $1 \%$ (by mass) of HP-GOS to rats, the growth of Bifidobacterium bifidum and B. longum in the gut increased most rapidly up to $12 \mathrm{~h}$, and thereafter the increase was slow. Therefore, $1 \%$ HP-GOS was found to be acceptable for the growth of probiotic bacteria. Groups of animals that were orally administered HP-GOS and bifidobacteria during the study, and the group administered HP-GOS during the 2nd (days 13-15) and 4th (days 28-30) period of the study had significantly $(p<0.05)$ higher numbers of bifidobacteria in faeces than groups receiving a single dose of bifidobacteria. HP-GOS affected the expression of genes encoding glucagon-like peptide-1 (GLP-1) and peptide YY (PYY). There was a significant upregulation of GLP-1 and PYY mRNA with HP-GOS and bifidobacteria intake. We propose that the prebiotic properties of HP-GOS are potentially valuable for the production of functional foods for human consumption.
\end{abstract}

Key words: high-purity galactooligosaccharides, bifidobacteria, genes encoding GLP-1 and PYY peptides

\section{Introduction}

There has been an increasing interest in the regulation of colonic microflora in order to improve the host's health. This has been achieved traditionally by dietary inclusion of live microbes as food supplements known as probiotics. An alternative approach involves the consumption of food ingredients known as prebiotics. Prebiotics may provide advantages to probiotic bacteria in the gastrointestinal tract and additionally exert direct effects on the microflora in the large intestine (1).
Galactooligosaccharides (GOS) that consist of 3-10 molecules of galactose and glucose are known to facilitate the growth of desirable intestinal microflora and are considered as potent non-digestible prebiotics (2). Commercial GOS that contain complex mixtures of oligosaccharides with different glycosidic linkages and degrees of polymerization are usually synthesized by enzymatic transgalactosylation of lactose by $\beta$-galactosidases from various sources such as yeast, fungi or bacteria $(3,4)$. In addition, these kinds of products can also contain transgalactosylated oligosaccharides, unreacted lactose, glu-

*Corresponding authors: Phone: +82 23290 5639; E-mail: ypark@dongguk.edu (in vivo experiment design); suh1960@korea.ac.kr (in vitro experiment design) 
cose and galactose, which do not have prebiotic properties but only the caloric value (5).

The most efficient process to produce high-purity GOS (HP-GOS) is yeast fermentation of sugars such as glucose, galactose and lactose (6). Cardelle-Cobas et al. (7) first reported the production of non-monosaccharides and HP-GOS by repeated batch fermentation with immobilized yeast cells. A GOS syrup of an increased purity was produced by immobilized $\beta$-galactosidase from Penicillium expansum F3 and subjected to fermentation by Saccharomyces cerevisiae L1 and Kluyveromyces lactis L3 (8). This was a feasible industrial process to produce high-purity GOS.

Among numerous non-digestible carbohydrate-based prebiotics, convincing scientific evidence for suitability for use as prebiotics exists only for inulin/oligofructose and GOS (9). Studies of the prebiotic effects of GOS and FOS in humans have shown that a daily dose of $4-20 \mathrm{~g}$ significantly increases the population of lactobacilli and bifidobacteria in the gut (10). Other effects, such as hypocholesterolemic effects, prevention of colon cancer, and enhancement of calcium absorption have been described $(11,12)$. Numerous studies have reported data on the effects of non-digestible oligosaccharides (NDOs) and dietary fibre content on serum cholesterol and lipid levels; however, only a limited number of reports indicate positive effects of GOS (13) or inulin (14) on serum cholesterol metabolism in humans. Yamashita et al. (15) suggested first that dietary inclusion of fructooligosaccharides demonstrated hypocholesterolemic effect in diabetic subjects.

In this paper, the ability of HP-GOS to support the in vitro growth of selected strains of probiotic bacteria, namely Lactobacillus acidophilus, Lactobacillus casei, Bifidobacterium bifidum and Bifidobacterium longum, is investigated. In addition, it was determined whether oral administration of HP-GOS affected the growth of bifidobacteria, as well as serum cholesterol and nitrogen levels and the expression of gene encoding glucagon-like peptide-1 (GLP-1) and tyrosine-tyrosine peptide (PYY), which act as significant modulators of appetite via their peripheral effects (on the vagus nerve) and/or by influencing directly the arcuate nucleus in the rat.

\section{Materials and Methods}

\section{Materials}

HP-GOS, containing $75.18 \%$ of galactooligosaccharides (by mass), were obtained from Neo Cremar Co. Ltd, Seoul, Republic of Korea. Commercial GOS, Y-GOS (52.52 $\%$ GOS, by mass; Yakult Honsha, Tokyo, Japan), C-GOS (56.25 \% GOS, by mass; Doosan Corn Products Korea, Seoul, Republic of Korea), and Q-GOS (41.77 \% GOS, by mass; Samyang Genex, Inchon, Republic of Korea) were purchased from a local market in Seoul, Republic of Korea. A commercial $\beta$-galactosidase from Bacillus circulans was obtained from Bision Corporation (Seongnam, Republic of Korea).

\section{Production of GOS}

Batch reactions were performed by incubating $\beta$-galactosidase with a $40-45^{\circ}$ Brix lactose solution in a 100 -litre incubator shaker at $150 \mathrm{rpm}$. Lactose $(25 \mathrm{~kg})$ was dis- solved in distilled water $(60 \mathrm{~L})$, and $0.08 \%$ (by mass) $\beta$-galactosidase from Bacillus circulans was added to synthesize GOS at $55{ }^{\circ} \mathrm{C}$ and $\mathrm{pH}=6.0$ for $24 \mathrm{~h}$. All reactions were terminated by incubation at $100{ }^{\circ} \mathrm{C}$ for $10 \mathrm{~min}$ and the sugar profile was analyzed by high-performance liquid chromatography. To increase the GOS content, 100 $\mathrm{mL}$ of $20 \%$ (by mass) GOS syrup produced by enzymatic hydrolysis with $\beta$-galactosidase were fermented by $8 \%$ (by mass) of fresh yeast (Saccharomyces cerevisiae L1). The fermentation process was carried out in a shaking incubator at $100 \mathrm{rpm}$ and $30^{\circ} \mathrm{C}$ for $24 \mathrm{~h}$. After each fermentation cycle, cells were transferred to $20 \%$ (by mass) GOS syrup, which was then filtered and treated with active carbon for decolourization. Ion exchange chromatography using Amberlite $^{\circledast}$ CG-120-II column (Sigma-Aldrich, Buchs, Switzerland) was utilized for further purification. The pooled fractions were evaporated to $45^{\circ} \mathrm{Brix}$ and dried with a spray dryer. Lactose and HP-GOS were determined by an HPLC system with Waters ${ }^{\circledR} 2414$ refractive index detector (RID) (Waters Corporation, Milford, MA, USA) equipped with YMC-Pack Polyamine II column $(4 \mathrm{~mm} \times 250 \mathrm{~mm}$; YMC Co. Ltd, Kyoto, Japan), column heater $\left(30^{\circ} \mathrm{C}\right)$, and RID detector. Acetonitrile (64\%) was used as mobile phase.

\section{Bacterial strains and growth conditions}

Lactobacillus acidophilus DDS-1, L. casei KCTC 12452, Bifidobacterium bifidum KCTC 3357 and B. longum SJ 32 were obtained from the culture collection from the Korea Research Institute of Bioscience and Biotechnology, Daejeon, Republic of Korea. The cultures were grown at $37^{\circ} \mathrm{C}$ in modified peptone yeast extract fructose (PYF) medium without carbon source consisting of (in \%, by mass): yeast extract 1 , peptone 0.5 , $\mathrm{L}$-cysteine $\mathrm{HCl} 0.5$ and salt solution 4 (containing (in \%, by mass): $\mathrm{CaCl}_{2} 0.02, \mathrm{MgSO}_{4} 0.02$, $\mathrm{K}_{2} \mathrm{HPO}_{4} 0.1, \mathrm{KH}_{2} \mathrm{PO}_{4} 0.1, \mathrm{NaCl} 0.2$ and $\mathrm{Na}_{2} \mathrm{HPO}_{3} 1.0$ ) (16). The medium was supplemented with $0.5,1,2$ or $4 \%$ (by mass) GOS. Microplates were incubated anaerobically at $37^{\circ} \mathrm{C}$ in a GasPak ${ }^{\mathrm{TM}}$ container (BD (Becton, Dickinson and Company), Franklin Lakes, NJ, USA). The absorbance at $600 \mathrm{~nm}\left(A_{600 \mathrm{~nm}}\right)$ was recorded by the microplate reader at 0,24 and $48 \mathrm{~h}$. At $24 \mathrm{~h}$, after the measurement of $A_{600 \mathrm{~nm}}$ the plates were placed in the incubator to restore anaerobic conditions.

\section{Animals and diet}

The experimental protocol was reviewed and approved by Institutional Animal Care and Use Committee of Korea University. Four-week-old male Sprague Daw$\operatorname{ley}^{\circledast}(\mathrm{SD})$ rats were purchased from Daehan Biolink Co. Ltd. (Cheongju, Republic of Korea). The animals were kept in a room at $24^{\circ} \mathrm{C}$ and constant atmosphere with 60 $\%$ humidity and a 12-hour light/dark cycle. Rats were fed an AIN-93G diet based on the main ingredients of corn starch $(40 \%)$ and casein $(20 \%)(17)$. After an adaptation period, the rats were randomly divided into four groups $(N=8)$ : the control group (oral administration of saline), the HP-GOS group (oral administration of HP-GOS), the HP-GOS+BB group (oral administration of HP-GOS and bifidobacteria), and the BB group (oral administration of bifidobacteria). The groups were orally administrated HP-GOS (1.5 mL of the solution of $1 \mathrm{~g}$ of HP-GOS and/or $10^{9} \mathrm{CFU}$ bifidobacteria) daily for 5 weeks. 
Fresh faecal samples were collected weekly (equal mass from four rats per pool) in sterile flasks, and kept at $-80{ }^{\circ} \mathrm{C}$ for microbiological analysis. To count the total number of bifidobacteria, $3 \mathrm{~g}$ of faecal sample were diluted in $25 \mathrm{~mL}$ of dilution solution and an aliquot of $0.2 \mathrm{~mL}$ was spread on Petri dishes using BL agar. Colonies were incubated anaerobically during $2-3$ days at $37^{\circ} \mathrm{C}$ under anaerobic conditions and results were measured as the $\log$ CFU per gram of faecal sample.

At the end of the study, the rats were euthanized using $\mathrm{CO}_{2}$ asphyxiation and the liver, kidney and spleen were removed and weighed immediately. The body mass of each rat was measured every week for 5 weeks and the mass of each organ was expressed as $100 \mathrm{~g}$ of body mass.

\section{Blood analysis}

Blood samples were collected into non-heparinized serum separator tubes. Serum triglycerides (TGs), total cholesterol (TC), and high-density lipoprotein cholesterol (HDL-C) levels were measured by using a FUJI Dri-Chem 3500 system (Fuji Photo Film Co., Osaka, Japan). Concentration of low-density lipoprotein cholesterol (LDL-C), in $\mathrm{mg}$ per $100 \mathrm{~mL}$, was calculated according to the method of Friedewald et al. (18) as follows:

$$
\gamma(\text { LDL-C })=\gamma(\text { TC })-\gamma(\text { HDL-C })-(\gamma(\text { TG }) / 5)
$$

\section{RNA extraction and real-time PCR}

Total RNA was obtained from the intestine samples by using TRIzol reagent (Invitrogen, Carlsbad, CA, USA) according to the manufacturer's protocol. Reverse transcription was performed by using $1 \mu \mathrm{g}$ of total RNA with first strand cDNA synthesis kit for real-time polymerase chain reaction (RT-PCR, Invitrogen) with oligo (dT) 15 as a primer (Invitrogen). After cDNA synthesis, real-time PCR was performed using a Power SYBR ${ }^{\circledast}$ Green PCR Master Mix kit (Applied Biosystems, Foster City, CA, USA). Quantitative analysis was carried out using StepOne plus software v. 2.0 (Applied Biosystems). Results were normalized to a validated control gene, $\beta$-actin, using the $\Delta \Delta \mathrm{Ct}$ method (19). Using primers to interrogate proglucagon and PYY, RT-PCR was performed by a method reported previously (20). The following primers were used for GLP-1 and PYY: proglucagon (NM-012707.2): forward primer: 5'-ATGCGGACGAATACATTTCC-3', reverse primer: 5'-CTCAGGGCGGTAACTTCAAA-3'; PYY (NM_001034080.1): forward primer: 5'-CAGCGGTATGGGAAAAGAGA-3', reverse primer: 5'-CATGCAAGTGAAGTCGGTGT-3'; $\beta$-actin (NM-031144.3): forward primer: $5^{\prime}$-GCTACAGCTTCACCACCACA-3', reverse primer: 5'-TGCCGATAGTGATGACCTGA-3'.

\section{Statistical analysis}

All statistical analyses were performed using the Statistical Package for Social Sciences, v. 12.0 (SPSS Inc., Chicago, IL, USA). The statistical significance of differences was determined using one-way ANOVA at a significance level of $p<0.05$. All data were significant at $95 \%$ level and reported as the mean value \pm standard deviation (S.D.).

\section{Results and Discussion}

\section{GOS content before and after enzymatic hydrolysis and fermentation}

Table 1 summarizes the content of saccharides during different stages of GOS preparation, i.e. the enzymatic hydrolysis by $\beta$-galactosidase and fermentation by $S$. cerevisiae. After treatment by $\beta$-galactosidase, GOS content increased from 0 to $51.0 \mathrm{~g}$ per $100 \mathrm{~g}$, and lactose mass fractions decreased from 99.2 to $21.3 \mathrm{~g}$ per $100 \mathrm{~g}$ (Table 1). Monosaccharide (glucose and galactose) mass fractions also increased from 0.8 to $27.7 \mathrm{~g}$ per $100 \mathrm{~g}$ after the enzymatic reaction; however, these monosaccharides were completely removed by fermentation with $S$. cerevisiae, whereas lactose levels were slightly increased. In order to increase the purity of GOS, fermentation process was utilized. After fermentation, glucose and galactose mass fractions decreased from 27.7 to $0.0 \mathrm{~g}$ per $100 \mathrm{~g}$ (Fig. 1 and Table 1). The purity of the GOS preparation increased

Table 1. Saccharide content during galactooligosaccharide (GOS) production

\begin{tabular}{|c|c|c|c|}
\hline \multirow{2}{*}{ Process } & $w($ monosaccharide $)$ & $w$ (lactose) & $w(\mathrm{GOS})$ \\
\hline & $\begin{array}{l}\mathrm{g} / 100 \mathrm{~g} \\
\end{array}$ & $\overline{\mathrm{g} / 100 \mathrm{~g}}$ & $\overline{\mathrm{g} / 100 \mathrm{~g}}$ \\
\hline Raw material & $0.8 \pm 0.1$ & $99.2 \pm 2.6$ & 0.0 \\
\hline $\begin{array}{l}\text { After enzyme } \\
\text { reaction }\end{array}$ & $27.7 \pm 1.8$ & $21.3 \pm 1.0$ & $51.0 \pm 3.3$ \\
\hline $\begin{array}{l}\text { After fermentation } \\
\text { with S. cerevisiae L1 }\end{array}$ & 0.0 & $26.4 \pm 1.3$ & $73.6 \pm 2.1$ \\
\hline
\end{tabular}

Values are expressed as mean \pm standard deviation
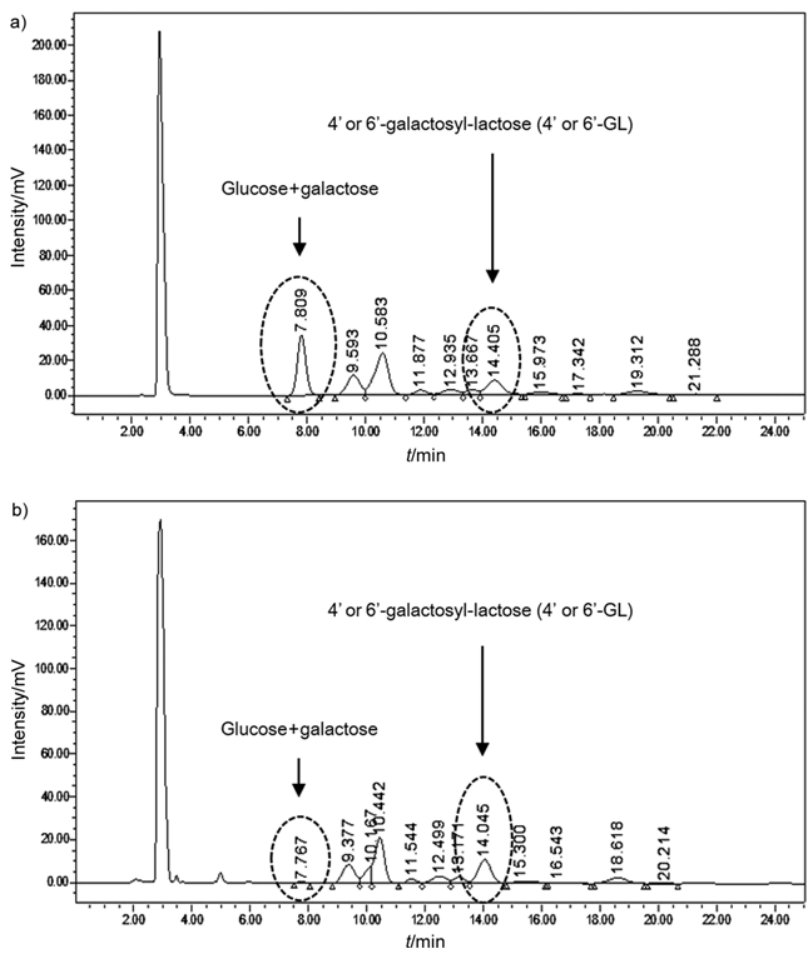

Fig. 1. Carbohydrate profile: a) before and b) after the fermentation with Saccharomyces cerevisiae L1 
from 51.0 to $73.6 \mathrm{~g}$ per $100 \mathrm{~g}$ after fermentation with $S$. cerevisiae (Table 1), verifying that HP-GOS were successfully produced using the two-step enzymatic hydrolysis and fermentation by yeast.

For the production of HP-GOS, selective fermentation for a given microorganism was characterized. During the fermentation, ethanol may be produced depending on the used microorganism, which at toxic volume fractions may compromise the activity of the microorganism. $S$. cerevisiae was used to increase the purity of the mixture of GOS obtained by enzymatic hydrolysis with $\beta$-galactosidase from Bacillus circulans, with complete removal of the monosaccharides (21). The same approach was adopted for the production of GOS mixture from B. bifidum biomass (9). In a previous research, Kluyveromyces marxianus improved the purity of a GOS mixture produced by $\beta$-galactosidase from $B$. circulans from 38 to $97 \%$ by selective fermentation of mono- and disaccharides (including lactose) (6). With a combined use of S. cerevisiae and K. lactis the purity of a GOS mixture produced by $\beta$-galactosidase from Penicillium expansum increased from 29 to 98 $\%$ (8). In this work, HP-GOS were produced by fermentation with S. cerevisiae (Table 1 and Fig. 1), which increased the GOS content from 51.0 to $73.6 \mathrm{~g}$ per $100 \mathrm{~g}$ after fermentation with $S$. cerevisiae.

\section{Utilization of GOS by intestinal bacteria in vitro}

HP-GOS comprise substances with structural differences and have considerably greater prebiotic potential compared to a commercially available GOS mixture. Fig. 2 shows the growth of intestinal bacteria in a medium containing various commercial GOS. In order to confirm that the growth was dependent on GOS utilization, strains were also inoculated into PYF basal medium containing $1 \%$ HP-GOS, Y-GOS, C-GOS or Q-GOS as the carbohydrate source. During the early stages of growth (after $12 \mathrm{~h}$ ), all strains exhibited a similar growth rate without significant differences. All strains (L. acidophilus, L. casei, B. longum and B. bifidum) in a medium containing HP-GOS had a higher cell growth rate than the strains grown in the media containing commercial GOS after 12 $\mathrm{h}$ of culture. These results suggest that HP-GOS serve as a good substrate and carbon source for supporting the growth of probiotic bacteria.

Growth curves for the given strains grown anaerobically in the medium without GOS or with $0.5,1,2$ or $4 \%$ (by mass) GOS are shown in Fig. 3. L. acidophilus and L. casei were able to grow at all the tested GOS mass fractions, both reaching a maximum $A_{600 \mathrm{~nm}}$ of 1.15 after $36 \mathrm{~h}$ of growth. Cell growth was increased with an increase in HP-GOS mass fraction. Growth of B. bifidum and B. long$u m$ increased rapidly until $12 \mathrm{~h}$ and then continued increasing slowly. Therefore, HP-GOS mass fractions above $1 \%$ were found to be acceptable for the growth of probiotic bacteria.

Structural differences of GOS vary notably depending on the conditions and source of enzymes used for their synthesis (HP-GOS and Y-GOS were produced from 4 '- or 6'-galactosyl-lactose, and C-GOS and Q-GOS from $4^{\prime}$-galactosyl-lactose) (4), which affects the fermentation process as well as their prebiotic properties. Studies of
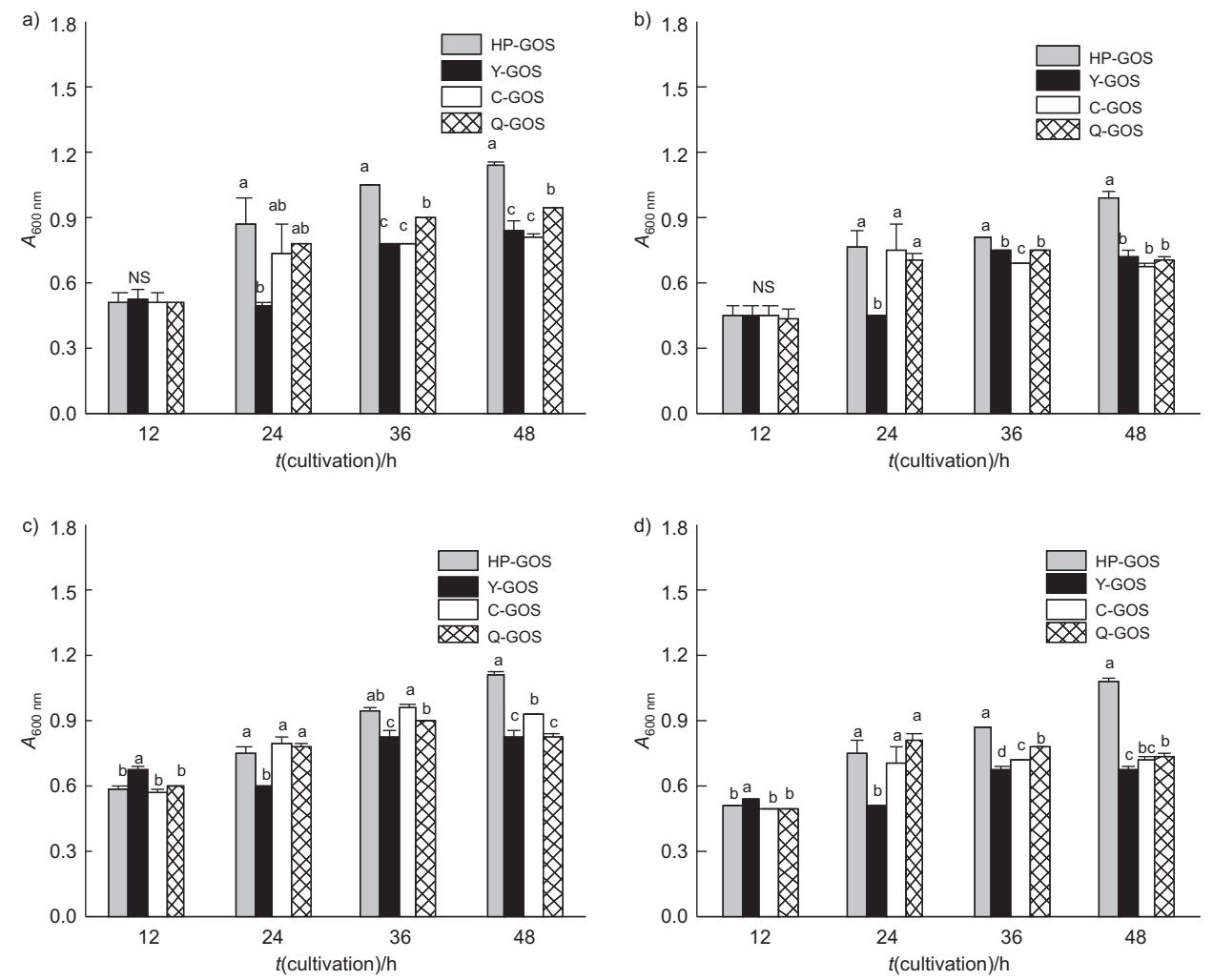

Fig. 2. Growth of: a) L. acidophilus, b) L. casei, c) B. bifidum and d) B. longum in modified PYF broth containing $1 \%$ (by mass) of various commercial galactooligosaccharides (GOS). Bars represent the standard error of triplicate measurements. Different letters indicate significant differences at $\mathrm{p}<0.05$ 

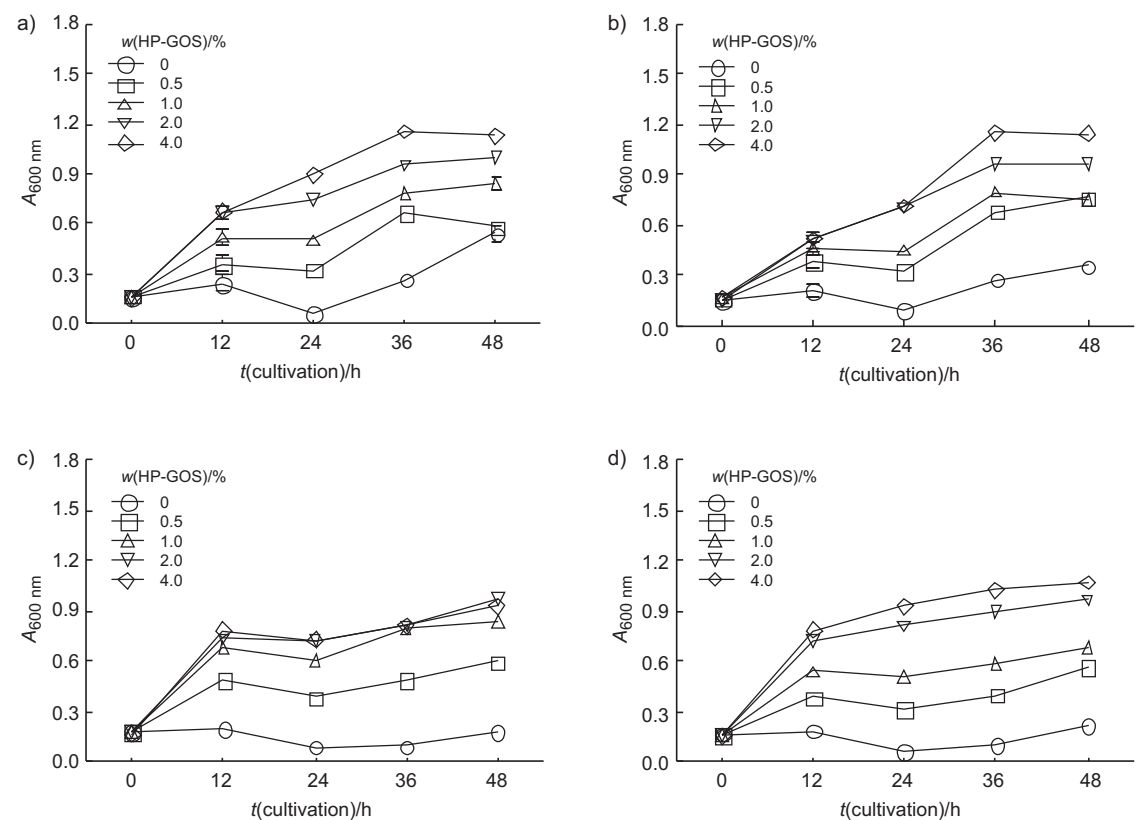

Fig. 3. Growth of: a) L. acidophilus, b) L. casei, c) B. bifidum and d) B. longum in modified PYF broth containing various mass fractions of high-purity galactooligosaccharides (HP-GOS). Bars represent the standard error of triplicate measurements

GOS utilization by bacteria have shown that different strains vary in their ability to ferment GOS, with individual strains exhibiting specific substrate preferences $(22$, 23).

We additionally analyzed the utilization of GOS by various probiotic bacteria (Fig. 2). L. acidophilus, L. casei, B. bifidum and $B$. longum had a higher cell growth rate when utilizing HP-GOS in comparison with commercial GOS (Fig. 2), suggesting that 4'- or 6'-galactosyl-lactose may be a more suitable substrate for these strains. The utilization of GOS by a number of probiotic bacteria has been extensively analyzed $(24,25)$. It has been shown that 4 '-galactosyl-lactose is selectively utilized by all the Bifidobacterium strains tested, compared with lactulose and raffinose, whose specificity is less noticeable. Other studies have also shown that some strains of Lactobacillus, Bacteroides and Clostridium ferment GOS, and that transgalactosylated disaccharides may even be better substrates for these bacteria (26). Some bacterial species can ferment both $4^{\prime}$ and 6 '-galactosyl-lactose, although there are some differences and the growth of bacteria is dose-dependent.

As shown in Fig. 3, B. bifidum and B. longum utilized HP-GOS more rapidly than L. acidophilus and L. casei. It is considered that the utilization of non-digestible oligosaccharides (NDOs) by bifidobacteria is mediated by the hydrolyzing enzymes produced by these strains. Many Bifidobacterium strains produce glycolytic enzymes that hydrolyze a wide range of monosaccharides and various glycosidic bonds, while the activities of the enzymes from other enteric bacteria such as Lactobacillus, Escherichia coli and Streptococcus are less varied and are weaker than those from Bifidobacterium (27).

\section{Changes in body mass, organ mass and serum parameters}

Changes in body mass and organ mass of the rats in control, HP-GOS, HP-GOS+BB and BB groups are shown in Table 2. No significant differences in body mass were found among the three groups. The changes in the masses of the liver and other internal organs of the rats after a 5 -week administration of each diet are shown in Table 3.

Table 2. Changes in body mass of rat after treatment with galactooligosaccharides and/or bifidobacteria

\begin{tabular}{lccccc}
\hline & \multicolumn{5}{c}{$t /$ week } \\
\cline { 2 - 6 } Group & 1 & 2 & 3 & 4 & 5 \\
\cline { 2 - 6 } & \multicolumn{5}{c}{$m / g$} \\
\hline Control & $44.7 \pm 1.0$ & $90.8 \pm 2.7$ & $147.7 \pm 5.2$ & $201.4 \pm 7.4$ & $230.5 \pm 6.1$ \\
HP-GOS & $42.5 \pm 2.0$ & $82.0 \pm 2.2$ & $129.5 \pm 4.7$ & $176.5 \pm 6.6$ & $210.6 \pm 7.0$ \\
BB & $43.5 \pm 1.5$ & $88.3 \pm 3.3$ & $139.6 \pm 3.1$ & $193.0 \pm 7.9$ & $219.0 \pm 8.2$ \\
HP-GOS+BB & $45.2 \pm 1.9$ & $90.3 \pm 3.3$ & $147.0 \pm 5.1$ & $196.6 \pm 5.8$ & $224.3 \pm 6.0$ \\
\hline
\end{tabular}

Values are expressed as mean \pm standard deviation. Control=oral administration of saline, HP-GOS=oral administration of high-purity galactooligosaccharides, $\mathrm{BB}=$ oral administration of bifidobacteria, HP-GOS+BB= oral administration of HP-GOS and bifidobacteria

Table 3. Changes of organ mass of rat after treatment with galactooligosaccharides and/or bifidobacteria

\begin{tabular}{lcccc}
\hline \multirow{2}{*}{ Organ } & \multicolumn{4}{c}{$w /(\mathrm{g} / 100 \mathrm{~g})$} \\
\cline { 2 - 5 } & Control & HP-GOS & BB & HP-GOS+BB \\
\hline Liver & $9.0 \pm 0.1$ & $8.4 \pm 0.5$ & $8.7 \pm 0.4$ & $8.9 \pm 0.2$ \\
Kidney & $2.3 \pm 0.1$ & $2.1 \pm 0.1$ & $2.3 \pm 0.1$ & $2.3 \pm 0.2$ \\
Spleen & $0.7 \pm 0.0$ & $0.6 \pm 0.0$ & $0.8 \pm 0.0$ & $0.7 \pm 0.0$ \\
\hline
\end{tabular}

Values are expressed as mean \pm standard deviation. Control=oral administration of saline, HP-GOS=oral administration of high-purity galactooligosaccharides, $\mathrm{BB}=$ oral administration of bifidobacteria, HP-GOS+BB=oral administration of HP-GOS and bifidobacteria 
No differences were observed in the masses of the liver, spleen and kidney in relation to the body mass in all groups.

Serum glucose, protein, aspartate aminotransferase (AST), alanine aminotransferase (ALT) and lipid profiles are shown in Table 4. Groups administered HP-GOS+BB had significantly different AST and ALT levels compared with the control group or the group administered HP-GOS, respectively $(p<0.05)$. However, the ALT and AST levels of the group administered HP-GOS+BB were in the normal range for SD rats (17.30-19.77 and 74.4-80.4 U/L, respectively) (28). There were no significant differences in the lipid profiles (total cholesterol, HDL cholesterol and triacyglycerol) among the groups.

\section{Enumeration of bifidobacteria in rat faeces}

Fig. 4 shows the total bifidobacteria counts in rat faeces, expressed in log CFU per g of faeces, during four periods of the study. The groups that were orally administered HP-GOS and bifidobacteria had significantly $(p<0.05)$ higher counts during all four periods, while the group receiving HP-GOS had higher counts in the 2nd and 4th period only in comparison with the control and $\mathrm{BB}$ group. In the 2nd and 3rd periods, the same trend was observed in groups administered HP-GOS and HP-GOS+BB. During the entire period, oral administration of HP-GOS+BB resulted in higher bifidobacteria counts than the oral administration of control or single administration of bifidobacteria. There was no significant difference in bifidobacteria counts between the HP-GOS+BB group and the HP-GOS group in the 2nd and 4th periods.

Bifidobacteria in rat faecal samples were counted in the HP-GOS groups with or without bifidobacteria. Our results indicated a positive effect in the synbiotic group (HP-GOS+BB) during the test periods. It is known that most bifidobacteria strains of human intestinal origin can readily use galactooligosaccharides; however, only a few strains from other genera, such as lactobacilli, possess this ability $(24,26)$. As far as the effects of probiotic consumption on the bifidobacterial population are concerned, similar results have been observed in children and adults. Benno and Mitsuoka (29) reported an increase in the counts of bifidobacteria as well as a remarkable decrease in the counts of clostridia in adult human subjects consuming a daily dose of $B$. longum.

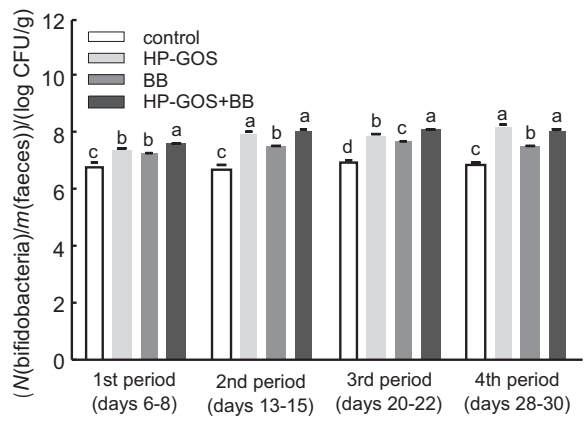

Fig. 4. Number of total bifidobacteria in rat faeces, expressed as mean values of log colony-forming units (CFU) per $g$ of wet faeces, $N=6$. Bars represent the standard error of triplicate measurements. Different letters indicate significant differences at $p<0.05$. HP-GOS=high-purity galactooligosaccharides, $B B=$ bifidobacteria

\section{Expression of genes encoding GLP-1 and PYY in ileum}

There was an approx. 1.6-fold increase in PYY mRNA levels in the ileum of rats administered GOS+BB (Fig. 5), which was significantly higher than in the other groups $(\mathrm{p}<0.05)$. Similarly, GLP-1 mRNA levels in the ileum of rats administered GOS+BB and only bifidobacteria were 1.5- and 1.6-fold higher, respectively, than in rats fed normal diet. There was a significant upregulation of GLP-1 and PYY mRNA with GOS+BB intake.

Endocrine cells in the intestinal mucosa secrete peptides involved in the regulation of food intake and/or pancreatic function; the latter are known as incretins $(30,31)$. Endocrine L cells are distributed throughout the intestinal tract, and are predominantly present in the caeco-colon, where fermentation of inulin-type fructans occurs (32). GLP-1 and PYY, which are released from intestinal L cells, modulate appetite and thus reduce food intake (33). The ability of prebiotic fibre to increase the proglucagon mRNA levels and GLP-1 secretion is well supported $(34,35)$. Increased proglucagon expression typically takes place when caecal mass is increased due to the markedly increased bacterial fermentation that occurs with the consumption of prebiotics $(34,35)$. It is interesting to note that the fibre-containing prebiotic diet appears to have acute and lasting effects on the ability of L cells to produce and secrete GLP-1 and PYY. In the current study, measurements of GLP-1 and PYY levels were performed

Table 4. Serum levels of glucose, total protein, AST, ALT, and lipid profiles of rats

\begin{tabular}{|c|c|c|c|c|c|c|c|c|}
\hline \multirow{2}{*}{ Group } & $\gamma$ (glucose) & $\gamma$ (total protein) & AST & ALT & $\gamma(\mathrm{TC})$ & $\gamma($ HDL-C) & $\gamma(\mathrm{LDL}-\mathrm{C})$ & $\gamma(\mathrm{TG})$ \\
\hline & $\mathrm{mg} / \mathrm{dL}$ & $\mathrm{g} / \mathrm{dL}$ & $\overline{\mathrm{U} / \mathrm{L}}$ & $\overline{\mathrm{U} / \mathrm{L}}$ & $\overline{\mathrm{mg} / \mathrm{dL}}$ & $\mathrm{mg} / \mathrm{dL}$ & $\mathrm{mg} / \mathrm{dL}$ & $\overline{\mathrm{mg} / \mathrm{dL}}$ \\
\hline Control & $110.7 \pm 2.6$ & $18.62 \pm 0.07$ & $74.4 \pm 2.2^{b}$ & $18.6 \pm 0.6^{\mathrm{ab}}$ & $79.2 \pm 2.5$ & $52.7 \pm 2.8$ & $11.4 \pm 3.0$ & $75.3 \pm 3.0$ \\
\hline HP-GOS & $111.5 \pm 5.4$ & $19.77 \pm 0.09$ & $79.6 \pm 0.8^{\mathrm{ab}}$ & $19.8 \pm 0.7^{\mathrm{a}}$ & $83.8 \pm 2.5$ & $56.2 \pm 2.3$ & $14.6 \pm 1.6$ & $77.7 \pm 1.7$ \\
\hline BB & $104.0 \pm 1.4$ & $18.42 \pm 0.09$ & $75.2 \pm 1.6^{\mathrm{ab}}$ & $18.4 \pm 0.9^{\mathrm{ab}}$ & $78.7 \pm 1.6$ & $54.6 \pm 2.0$ & $10.5 \pm 3.9$ & $73.5 \pm 1.7$ \\
\hline HP-GOS+BB & $114.5 \pm 4.4$ & $17.30 \pm 0.08$ & $80.4 \pm 1.7^{\mathrm{a}}$ & $17.3 \pm 0.6^{\mathrm{b}}$ & $85.3 \pm 0.6$ & $56.0 \pm 1.5$ & $16.0 \pm 0.8$ & $77.8 \pm 1.3$ \\
\hline
\end{tabular}

Values are expressed as mean \pm standard deviation, $N=8$. Mean values with different letters in superscript within the column are significantly different at $\mathrm{p}<0.05$ by Duncan's multiple range tests. AST=aspartate aminotransferase, ALT=alanine aminotransferase, $\mathrm{TC}=$ total cholesterol, HDL-C=high-density lipoprotein cholesterol, LDL-C=low-density lipoprotein cholesterol, TG=triglyceride. Control=oral administration of saline, HP-GOS=oral administration of high-purity galactooligosaccharides, $\mathrm{BB}=\mathrm{oral}$ administration of bifidobacteria, HP-GOS+BB=oral administration of HP-GOS and bifidobacteria 

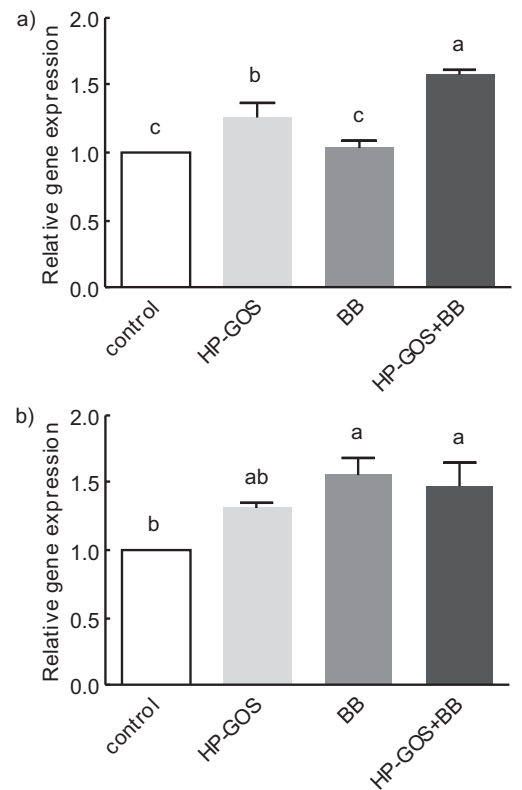

Fig. 5. Expression of genes encoding PYY and GLP-1 in the ileum of mice orally administered saline (control), high-purity galactooligosaccharides (HP-GOS), bifidobacteria (BB), and high-purity GOS+bifidobacteria (HP-GOS+BB) for 4 weeks, $N=8$. Bars represent mean value \pm standard error of the mean (SEM). Different letters indicate significant differences at $\mathrm{p}<0.05$

at the end of a 5-week period, when GOS as prebiotics were administered as part of the diet; however, we additionally found higher expression of genes encoding GLP-1 and PYY in the HP-GOS group with or without B. bifi$d u m$ at the end of the period in which the high fat-based diet was administered (Fig. 5).

It is acknowledged that an optimum balance in microbial populations in the digestive tract is associated with good nutrition and health, and that this may be achieved by the consumption of probiotics. In particular, HP-GOS exhibit a greater prebiotic activity than other commercial GOS.

\section{Conclusion}

High-purity galactooligosaccharides (HP-GOS) were successfully produced using a two-step process, enzymatic hydrolysis and fermentation by yeast. They were found to serve as a good substrate and carbon source for supporting the growth of enteric bacteria, compared with other commercial GOS. The beneficial effect of regular intake of HP-GOS is attributed to the intestinal survival of probiotic Lactobacillus and Bifidobacterium strains. The health benefits associated with the consumption of HP-GOS in humans include improvement of intestinal tract health, increase in the expression of genes encoding GLP-1 and PYY, decrease in the risk of certain cancers, blood pressure control, and reduction of serum cholesterol levels. On the basis of our findings, we propose that the prebiotic properties of HP-GOS are valuable in the production of potential health-enhancing foods and supplements, and that HP-GOS may be used as a functional food ingredient for human consumption.

\section{Acknowledgements}

This research was supported by High Value-Added Food Technology Development Program, Ministry of Agriculture, Food and Rural Affairs, Sejong, Republic of Korea.

\section{Disclosures}

None of the authors of this study has any financial interest or conflict with industries or parties.

\section{References}

1. Gibson GR, Probert HM, Van Loo J, Rastall RA, Roberfroid MB. Dietary modulation of the human colonic microbiota: updating the concept of prebiotics. Nutr Res Rev. 2004;17: 259-75. http://dx.doi.org/10.1079/NRR200479

2. Sako T, Matsumoto K, Tanaka R. Recent progress on research and applications of non-digestible galacto-oligosaccharides. Int Dairy J. 1999;9:69-80. http://dx.doi.org/10.1016/S0958-6946(99)00046-1

3. Ekhart PF, Timmermans E. Techniques for the production of transgalactosylated oligosaccharides (TOS). Bull Int Dairy Found. 1996;313:59-64.

4. Otieno DO. Synthesis of $\beta$-galactooligosaccharides from lactose using microbial $\beta$-galactosidases. Compr Rev Food Sci Food Saf. 2010;9:471-82. http://dx.doi.org/10.1111/j.1541-4337.2010.00121

5. Mahoney RR. Galactosyl-oligosaccharide formation during lactose hydrolysis: a review. Food Chem. 1998;63:147-54. http://dx.doi.org/10.1016/S0308-8146(98)00020-X

6. Cheng CC, Yu MC, Cheng TC, Sheu DC, Duan KJ, Tai WL. Production of high-content galacto-oligosaccharide by enzyme catalysis and fermentation with Kluyveromyces marxianus. Biotechnol Lett. 2006;28:793-7. http://dx.doi.org/10.1007/s10529-006-9002-1

7. Cardelle-Cobas A, Corzo N, Olano A, Peláez C, Requena T, Ávila M. Galactooligosaccharides derived from lactose and lactulose: influence of structure on Lactobacillus, Streptococcus and Bifidobacterium growth. Int J Food Microbiol. 2011; 149:81-7. http://dx.doi.org/10.1016/j.ijfoodmicro.2011.05.026

8. Li Z, Xiao M, Lu L, Li Y. Production of non-monosaccharide and high-purity galactooligosaccharides by immobilized enzyme catalysis and fermentation with immobilized yeast cells. Process Biochem. 2008;43:896-9.

http://dx.doi.org/10.1016/j.procbio.2008.04.016

9. Goulas A, Tzortzis G, Gibson GR. Development of a process for the production and purification of $\alpha$ - and $\beta$-galactooligosaccharides from Bifidobacterium bifidum NCIMB 41171. Int Dairy J. 2007;17:648-56. http://dx.doi.org/10.1016/j.idairyj.2006.08.010

10. Rycroft CE, Fooks LJ, Gibson GR. Methods for assessing the potential of prebiotics and probiotics. Curr Opin Clin Nutr Metab Care. 1999;2:481-4.

http://dx.doi.org/10.1097/00075197-199911000-00008

11. Tuohy KM, Rouzaud GCM, Bruck WM, Gibson GR. Modulation of the human gut microflora towards improved health using prebiotics - assessment of efficacy. Curr Pharm Des. 2005;11:75-90. http://dx.doi.org/10.2174/1381612053382331

12. Perugino G, Trincone A, Rossi M, Moracci M. Oligosaccharide synthesis by glycosynthases. Trends Biotechnol. 2004;22: 


\section{1-7.}

http://dx.doi.org/10.1016/j.tibtech.2003.10.008

13. Hayashi M. Effects of $4^{\prime}$-galactosyllactose on lipid metabolism in human serum. Med Biol. 1989;119:15-8 (in Japanese).

14. Roberfroid MB, Delzenne NM. Dietary fructans. Annu Rev Nutr. 1998;18:117-43. http://dx.doi.org/10.1146/annurev.nutr.18.1.117

15. Yamashita K, Kawai K, Itakura M. Effects of fructo-oligosaccharides on blood glucose and serum lipids in diabetic subjects. Nutr Res. 1984;4:961-6. http://dx.doi.org/10.1016/S0271-5317(84)80075-5

16. Jaskari J, Kontula P, Siitonen A, Jousimies-Somer H, MattilaSandholm T, Poutanen K. Oat $\beta$-glucan and xylan hydrolysates as selective substrates for Bifidobacterium and Lactobacillus strains. Appl Microbiol Biotechnol. 1998;49:175-81. http://dx.doi.org/10.1007/s002530051155

17. Reeves PG, Nielsen FH, Fahey Jr GC. AIN-93 purified diets for laboratory rodents: final report of the American Institute of Nutrition ad hoc writing committee on the reformulation of the AIN-76A rodent diet. J Nutr. 1993;123:1939-51.

18. Friedewald WT, Levy RI, Fredrickson DS. Estimation of the concentration of low-density lipoprotein cholesterol in plasma, without use of the preparative ultracentrifuge. Clin Chem. 1972;18:499-502.

19. Livak KJ, Schmittgen TD. Analysis of relative gene expression data using real-time quantitiative PCR and the $2^{-\Delta \Delta C T}$ method. Methods. 25;2001:402-8. http://dx.doi.org/10.1006/meth.2001.1262

20. Maurer AD, Chen Q, McPherson C, Reimer RA. Changes in satiety hormones and expression of genes involved in glucose and lipid metabolism in rats weaned onto diets high in fibre or protein reflect susceptibility to increased fat mass in adulthood. J Physiol. 2009;587:679-91. http://dx.doi.org/10.1113/jphysiol.2008.161844

21. Hernández O, Ruiz-Matute AI, Olano A, Moreno FJ, Sanz ML. Comparison of fractionation techniques to obtain prebiotic galactooligosaccharides. Int Dairy J. 2009;19:531-6. http://dx.doi.org/10.1016/j.idairyj.2009.03.002

22. Barboza M, Sela DA, Pirim C, LoCascio RG, Freeman SL, German JB, et al. Glycoprofiling bifidobacterial consumption of galacto-oligosaccharides by mass spectrometry reveals strain-specific, preferential consumption of glycans. Appl Environ Microbiol. 2009;75:7319-25. http://dx.doi.org/10.1128/AEM.00842-09

23. Ignatova T, Iliev I, Kirilov N, Vassileva T, Dalgalarrondo Ml, Haertlé $\mathrm{T}$, et al. Effect of oligosaccharides on the growth of Lactobacillus delbrueckii subsp. bulgaricus strains isolated from dairy products. J Agric Food Chem. 2009;57:9496-502. http://dx.doi.org/10.1021/jf901684z
24. Ishikawa $\mathrm{F}$, Takayama $\mathrm{H}$, Matsumoto $\mathrm{K}$, Ito $\mathrm{M}$, Chonan $\mathrm{O}$, Deguchi $Y$, et al. Effects of $\beta$-( $1 \rightarrow 4)$-linked galactooligosaccharides on human fecal microflora. Bifidus. 1995;9:5-18.

25. Ohtsuka K, Benno Y, Endo K, Ueda H, Ozawa O, Uchida T, Mitsuoka T. Effects of 4'-galactosyl-lactose intake on human fecal microflora. Bifidus. 1989;2:143-9.

26. Tanaka R, Takayama H, Morotomi M, Kuroshima T, Ueyama $\mathrm{S}$, Matsumoto $\mathrm{K}$, et al. Effects of administration of TOS and Bifidobacterium breve 4006 on the human fecal flora. Bifidobacteria Microflora. 1983;2:17-24. http://dx.doi.org/10.12938/bifidus1982.2.1_17

27. Tochikura T, Sakai K, Fujoyoshi T, Tachiki T, Kumagai H. pNitrophenyl glycoside-hydrolyzing activities in bifidobacteria and characterization of $\beta$-D-galactosidase of Bifidobacterium longum 401. Agric Biol Chem. 1986;50:2279-86. http://dx.doi.org/10.1080/00021369.1986.10867744

28. Johnson-Delaney CA. Exotic companion medicine handbook for veterinarians. Idaho Falls, ID, USA: Wingers Publishing Incorporated; 1996.

29. Benno Y, Mitsuoka T. Impact of Bifidobacterium longum on human fecal microflora. Microbiol Immunol. 1992;36:683-94. http://dx.doi.org/10.1111/j.1348-0421.1992.tb02071.x

30. Druce MR, Small CJ, Bloom SR. Minireview: gut peptides regulating satiety. Endocrinology. 2004;145:2660-5. http://dx.doi.org/10.1210/en.2004-0089

31. Stanley S, Wynne K, Bloom S. Gastrointestinal satiety signals III. Glucagon-like peptide 1, oxyntomodulin, peptide YY, and pancreatic polypeptide. Am J Physiol-Gastr L. 2004;286: G693-7. http://dx.doi.org/10.1152/ajpgi.00536.2003

32. Drucker DJ. Biological actions and therapeutic potential of the glucagon-like peptides. Gastroenterology. 2002;122:531-44. http://dx.doi.org/10.1053/gast.2002.31068

33. Murphy KG, Dhillo WS, Bloom SR. Gut peptides in the regulation of food intake and energy homeostasis. Endocr Rev. 2006;27:719-27.

http://dx.doi.org/10.1210/er.2006-0028

34. Maurer AD, Eller LK, Hallam MC, Taylor K, Reimer RA. Consumption of diets high in prebiotic fiber or protein during growth influences the response to a high fat and sucrose diet in adulthood in rats. Nutr Metab. 2010;7:77-88. http://dx.doi.org/10.1186/1743-7057-7-77

35. Parnell JA, Reimer RA. Prebiotic fibres dose-dependently increase satiety hormones and alter Bacteroidetes and Firmicutes in lean and obese JCR:LA-cp rats. Br J Nutr. 2012;107: 601-13. http://dx.doi.org/10.1017/S0007114511003163 